\title{
Correlation between the Compressive, Tensile Strength of Old Concrete under Marine Environment and Prediction of Long-Term Strength
}

\author{
Weilai Yao, ${ }^{1}$ Shiyong Jiang, ${ }^{2}$ Wei Fei, ${ }^{1}$ and Tao Cai ${ }^{1}$ \\ ${ }^{1}$ Civil Engineering Department, Logistical Engineering University, Chongqing 401311, China \\ ${ }^{2}$ Training Department, Logistical Engineering University, Chongqing 401311, China \\ Correspondence should be addressed to Shiyong Jiang; jiangshiy@163.com
}

Received 22 March 2017; Accepted 3 May 2017; Published 25 May 2017

Academic Editor: Andrey E. Miroshnichenko

Copyright (C) 2017 Weilai Yao et al. This is an open access article distributed under the Creative Commons Attribution License, which permits unrestricted use, distribution, and reproduction in any medium, provided the original work is properly cited.

Compressive strength and tensile strength are important mechanical properties of concrete. The long-term strength of concrete under real service environment is an important parameter when evaluating existing buildings, which should also be properly considered in structural design. In this study, the relationship between compressive and splitting tensile strength of old concrete existing for long period under marine environment was investigated. At a deserted harbour, concrete cores samples were drilled by pairs in site. For each pair of samples, the two cores were drilled from the adjacent location and conducted to compressive, splitting tensile test, respectively. 48 compressive and splitting tensile strengths were finally obtained. From the test results, tensile strength presents general uptrend with compressive strength, and the two parameters are well positively correlated. Exponential model generally recommended by building codes or literatures is still capable of describing the relationship between compressive and tensile strength of old deteriorated concrete, when function parameters are properly determined. Based on statistical theory and the experimental result of this study, a method for predicting long-term tensile strength of concrete is developed and an example is given, which may provide a potential way to estimate long-term concrete strength under real marine environment.

\section{Introduction}

The value of tensile strength of concrete affects the performance of structures, such as the shear force resistance and the load-bearing capacity of anchors with concrete cone failure as decisive failure mode. Hence, as concrete compressive strength, tensile strength is another critical mechanical property, which should be appropriately considered in structure design. The real value of the in situ tensile and compressive strengths of concrete deteriorated under authentic service environments for long time provide a necessary basis for the evaluation of structures, especially for those, which have existed for long period already. Considering the complexity, cost, and time-consuming nature of performing tensile tests, many researchers and building guidelines are interested to predict the tensile strength from compressive strength and their relationship in a simplified method with satisfactory accuracy [1-5]. Most correlations proposed by building codes or literatures are based on normal curing conditions and testing age of 28 days. In reality, there are many different time-, load-, and environment-dependent impacts on concrete existing in real service conditions for long term. Therefore, the compressive-tensile strength relationship in building codes cannot be assumed without further observations and investigations $[5,6]$.

On the other hand, so far, the concrete strength is considered as time invariant, when conducting structural design and calculation. In this way, constructions should be completely reliable and the service life should be infinite, as long as $R>S$ ( $R$ and $S$ represent resistance and stress in broad sense) is satisfied in designing stage. But in fact, resistance of material, such as concrete strength, may degrade with time in outdoor environments, which leads to degradation of reliability and overall structure performance. In this respect, 
it is worthwhile to underline that the time-varying characteristics of concrete exposed to outdoor environment are necessary to be further researched. Moreover, in construction durability assessment or structure life prediction, the longterm concrete strength, along with its time-varying features, is essential information. However, it is not simple to carry out studies to research the changing law of concrete strength in long term, since it may takes several years or decades to run the tests.

Accelerated aging tests and simulative environmental tests are mainly adopted to study the environmental impacts on concrete strength. Li et al. [7] researched acidification corrosion depth and compressive strength of concrete subjected to sulphuric acid environments by accelerated tests. The results show that the remaining compressive strength values for the concrete exposed to $\mathrm{pH}=2$ and 3 sulphuric acid water environments and wet-dry cyclic sulphuric acid environment with $\mathrm{pH}=2$ are $74 \%, 72 \%$, and $80 \%$ of initial strength, respectively. An accelerated corrosion by a sulphate solution in a dry-wet cycle was introduced to simulate the external sulphate corrosion environment by Zhou et al. [8]. The accelerated corrosion test results indicate that the strength degradation of concrete by sulphate attack had a significant relation with the corrosion depth. Cai et al. [9] assessed the concrete strength and deformation property under artificial sea water erosion environment. Concrete stress and strain curve was researched with the number of wet and dry cycles of 0 times, 10 times, 20 times, 30 times, 40 times, 50 times, and 60 times. A biaxial concrete strength criterion was established taking into account the stress ratio and the number of dry-wet cycles. Ramli et al. [10] studied the environmental resistance of concrete incorporating coconut fibres. Three types of simulated aggressive environments were adopted: air environment in a tropical climate, alternate air, and seawater environments in a 14-day cycle and continuous immersion in seawater. Shang et al. [11] investigated mechanical properties of plain concrete and air-entrained concrete subjected to freeze-thaw cycles (F-T-C). The influences of F-T cycles on ultrasonic velocity and mechanical properties of air-entrained concrete and plain concrete were analysed. Also, accelerated aging test or simulative environmental test is adopted in [12-18], which shows that it is convenient and time saving to adopt such experimental method to study the environmental effects on concrete properties. However, there are apparent differences between real service condition and artificial environment, since the latter can merely reproduce several environmental factors, such as sulphate, chloride ion, acid, high temperature, and humidity. In fact, the real environment is far more intricate and cannot be simply represented by simulative environmental test. In addition, in the previous literatures above, the longest aging time was 365 days [17], which cannot be regarded as a long enough period when comparing to the working life in practical engineering. Moreover, tensile strength of concrete was scarcely discussed in those previous studies.

There are only a few existing studies that investigated long-term environmental effects on concrete strength under real service conditions. However, only compressive strength was researched. Ismail et al. [19] investigated compressive
TABLE 1: The atmosphere chloride content of Zhoushan city.

\begin{tabular}{lrrrrrrr}
\hline $\begin{array}{l}\text { Distance to sea } \\
(\mathrm{m})\end{array}$ & 2 & 100 & 140 & 200 & 260 & 340 & 500 \\
\hline $\begin{array}{l}\text { Mean } \\
\text { precipitation } \\
\text { value of } \\
\text { chloride per } \\
\text { day }\left(\mu \mathrm{g} / \mathrm{cm}^{2} \mathrm{~d}\right)\end{array}$ & 11.130 & 10.856 & 3.998 & 3.638 & 2.941 & 2.427 & 2.951 \\
\hline
\end{tabular}

strength loss of concrete exposed to outdoor environment by 6 year's monitoring. Studies by Mehta [20] Shekarchi et al. [21] and Washa and Wendt [22] discussed the longterm concrete compressive strength under actual marine environment. None of them addressed tensile strength and the correlation between compressive and tensile strength of concrete.

The major thrust of this study is to obtain both compressive and tensile strengths of concrete under real marine environment for long period (up to 61 years) and identify the correlation between the two mechanical properties. Concrete cores were drilled out by pairs at a deserted harbour in Zhoushan city, Zhejiang province, China. Every two cores of each pair were conducted in compressive and tensile splitting test, respectively; then, the relationship between long-term compressive and tensile strength was concluded. The applicability of compressive-tensile strength relationship recommended by literatures or building codes for concrete without deterioration (fresh concrete) was examined. A better fitted relationship function was presented. After that, based on statistical theory and a compressive strength predicting model from literature, a tensile strength predicting method was established and a calculating example was provided for interpreting, which may offer a potential way to estimate long-term tensile strength of concrete under real marine environment.

\section{Experimental Program}

2.1. Concrete Cores Drilling. Zhoushan is a coastal city in China. Constructions and buildings there are deteriorated by typical marine environment, like seawater, marine atmosphere, tidal waves, and so on. The yearly average temperature is 15 to 20 degrees Celsius. The content of chloride ion in atmosphere of Zhoushan city is given in Table 1.

Concrete cores samples were drilled from 4 different sites at a deserted harbour of Zhoushan city. Site A is the concrete slab of a deserted dock built in 1955. When tide rises, the distance between the dock slab and sea level is $4 \mathrm{~m}$ approximately. Site B is a large piece of plain concrete on seabeach, which was left as construction waste when nearby new harbour was established in 2011. Site C is a concrete pedestal of streetlight casted in 2000 . Site D is the reinforced concrete roof of a deserted building constructed in 2005. The above four sites (A, B, C, and D) which had existed for 61, 5,16 , and 11 years till our test began are in adjacent areas. All of them are not immersed by sea water due to their high enough places and in atmosphere all time. Concrete cores 


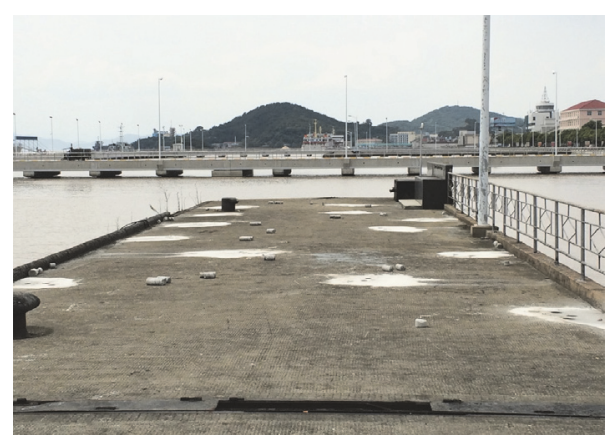

FIGURE 1: The cores drilling site.

drilled from each site were marked as group A, group B, group $\mathrm{C}$, and group $\mathrm{D}$, respectively.

In this study, the operations of drilling and testing refer to the technical specification for testing concrete strength with drilled core [23]. Location of steel bars was detected by magnetic spectroscopy steel detector and proper drilling places (away from bars) were selected, in order to avoid damage to reinforcement. Cores with diameter as $75 \mathrm{~mm}$ were mostly drilled, which are smaller than standards core samples in the formerly mentioned technical specification [23]. Another 4 standard cores with diameter as $100 \mathrm{~mm}$ were drilled, since the $75 \mathrm{~mm}$-diameter drilling barrel was severely worn out. The concrete cores were obtained by pairs. For each pair of samples, the two cores were conducted to compressive and tensile test respectively, aiming to investigate the relationship between compressive and tensile strengths. The 2 cores of each pair were drilled from close enough places, which ensures that they consist of same batch of concrete with identical deterioration. The place (site A) for drilling cores is shown in Figure 1.

2.2. Cores Processing. The drilled cores were carefully processed including incising and end faces dealing before mechanical tests.

2.2.1. Cores Incising. Based on the mentioned test specification [23], after processing, the height-diameter ratio of core samples should be 1 theoretically, which can value from 0.95 1.05 in actual operation. Incision machine with double parallel blades was used and the distance between two blades will determine the height of each core. Before incising, the distance of double blades was carefully adjusted and then fixed, in order to ensure that the height-diameter ratio of each core is in the allowed range as $0.95 \sim 1.05$. The incising procession is shown in Figure 2(a).

After incision, cores were paired up. Two cores of each pair were confirmed to be obtained from close enough locations. The matched cores were placed in pairs shown in Figure 2(b).

2.2.2. Cores Selecting and Loading Test Preparing. According to the test specification [23], there should be no more than 1 steel bar in qualified core and the diameter of steel bar should be less than $10 \mathrm{~mm}$. The possibly existing steel bar should be vertical to the shaft of core. Samples with obvious cracks or flaws were excluded. According to the above prerequisites, 96 eligible cores (48 pairs) were finally selected. The end faces of all cores were levelled. Belt grinder machine or polymer cement mortar was adopted to make end faces smooth and level, as shown in Figure 3(a).

The scales of each qualified core sample were measured. Vernier caliper was applied to measure the diameters. Diameter was measured twice for each core at two vertical places and the average value was adopted as the final diameter, which would be applied in the further strength calculation (Figure 3(b)). Steel tap was applied to measure the core height (Figure 3(c)). Lines were drawn on those samples that would be tensile split to indicate the failure areas, as shown in Figure 3(d).

2.3. Loading Test. All of the 96 core samples were numbered before loading test. Every two cores of each pair were the same batch of concrete and deteriorated by environment equally: one sample was conducted to compressive test, while the other was conducted to tensile splitting test. Two universal testing machines with measuring range as $500 \mathrm{KN}$ and $100 \mathrm{KN}$ are applied to compressive and tensile splitting test, respectively. Finally, 48 compressive strengths were obtained, as well as 48 tensile splitting strengths. Compressive and tensile splitting tests are shown in Figures 4(a) and 4(b).

Test information as serial number, sample scale, and the maximum applied force of each core sample is given in Table 2. Data number consists of a three-part code, and the aleph (A, B, C, and D) represents the group of samples, which also indicates the places where concrete cores were drilled. The second figure in data number presents the sequence of sample pair in each group. The third figure in data number indicates the type of mechanical experiment: 1 represents tensile splitting test and 2 represents compressing test. $d$ and $h$ represent the diameter and height of core sample, respectively; $d / h$ is the height-diameter ratio, which are all in the allowable range as $0.95 \sim 1.05 ; F$ is the maximum applied force of each sample in loading test.

2.4. Strength Calculation. According to the technical specification for testing concrete strength with drilled core [23], compressive strength of core sample was calculated as follows:

$$
f_{\mathrm{cu}, \mathrm{cor}}=\frac{F_{\mathrm{c}}}{A}
$$

where $f_{\text {cu,cor }}$ is compressive strength; $F_{c}$ is the measured maximum compressive force in the test; $A$ is the area of compressive section.

The tensile split strength was calculated as [23]

$$
f_{\text {cts }}=0.637 \cdot \frac{F_{\text {spl,cor }}}{A_{\text {ts }}} \text {, }
$$

where $f_{\text {cts }}$ is tensile splitting strength; $F_{\text {spl,cor }}$ is the measured maximum splitting force of each sample; $A_{\mathrm{ts}}$ is the area of split section; 0.637 is a coefficient derived from elastic theory. 


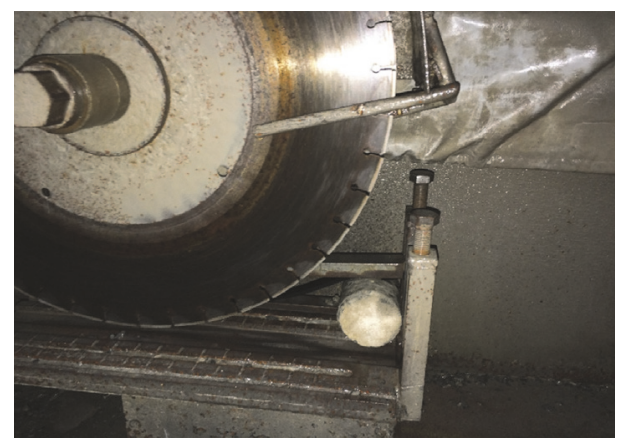

(a)

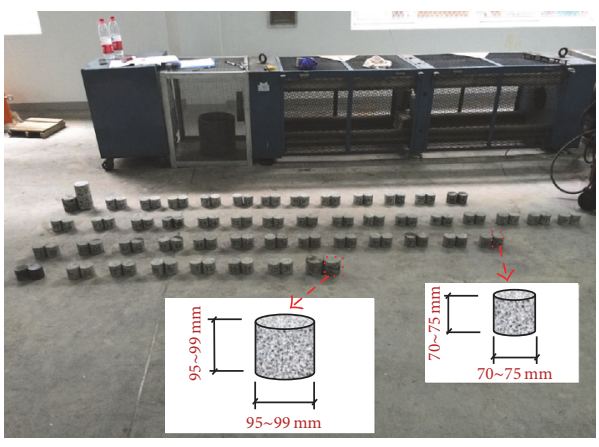

(b)

FIGURE 2: Incision progress and the incised cores.

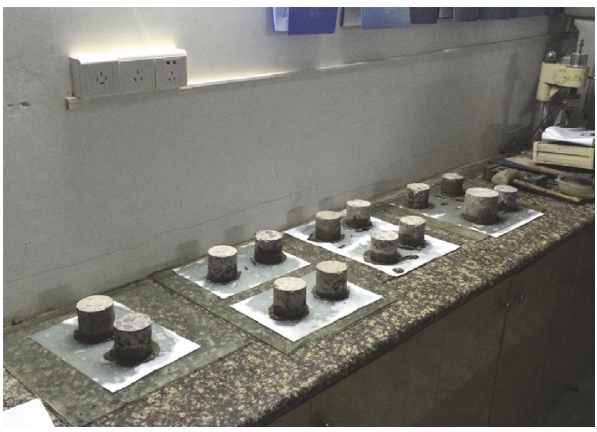

(a)

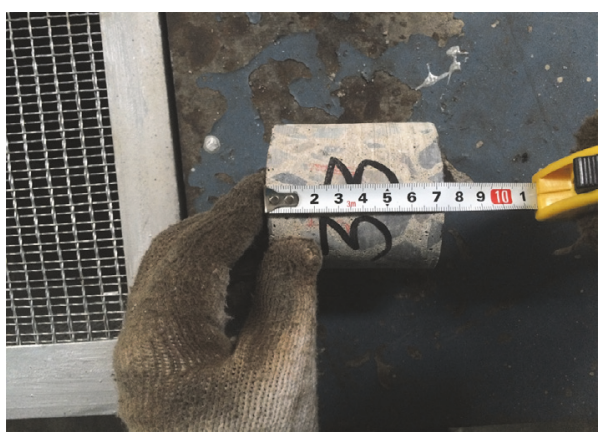

(c)

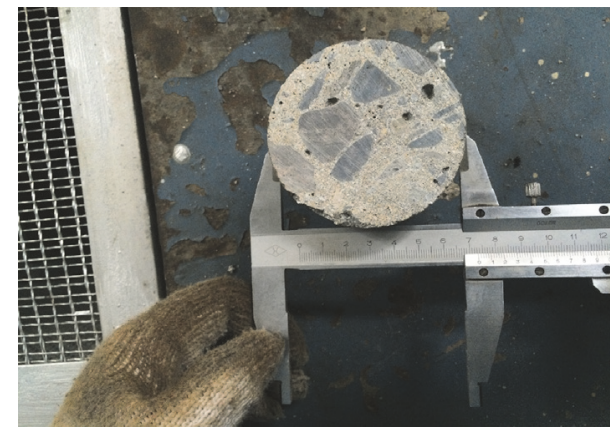

(b)

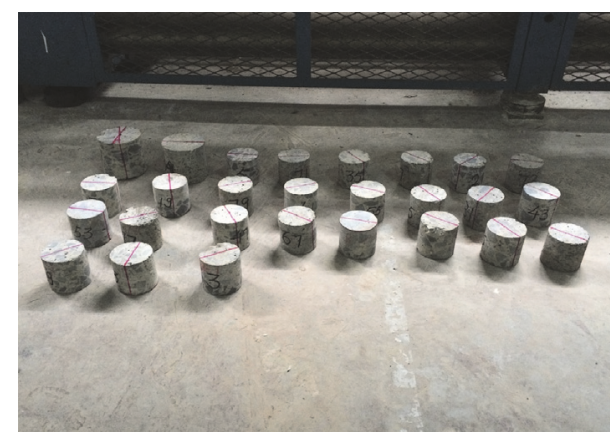

(d)

FIGURE 3: End face levelling, measuring scale, and preparing for loading tests.

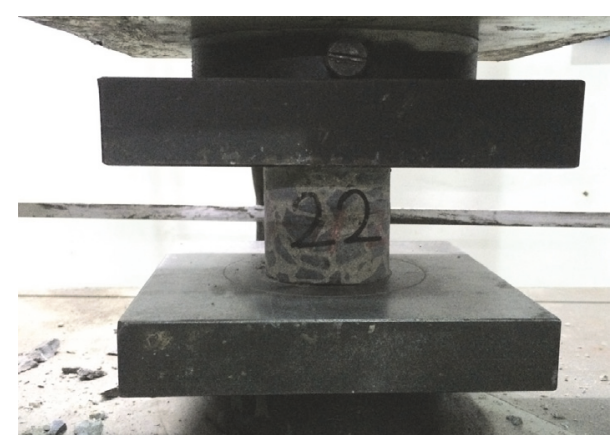

(a)

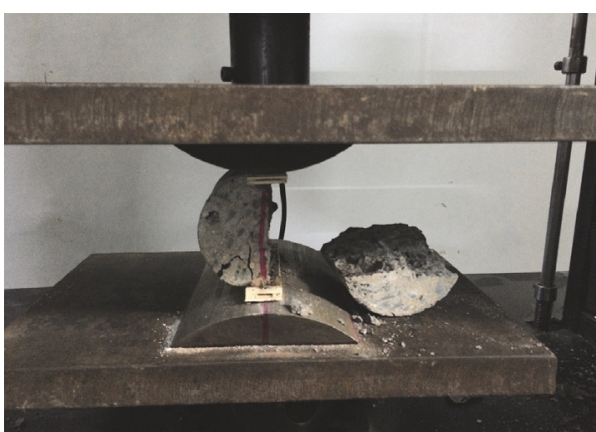

(b)

Figure 4: Loading test. 
TABLE 2: The primary data of experiment.

\begin{tabular}{|c|c|c|c|c|c|c|c|c|c|c|c|}
\hline Data number & Test type & $d / \mathrm{mm}$ & $h / \mathrm{mm}$ & $h / d$ & $F / \mathrm{KN}$ & Data number & Test type & $d / \mathrm{mm}$ & $h / \mathrm{mm}$ & $h / d$ & $F / \mathrm{KN}$ \\
\hline A-1-1 & Tensile splitting & 99.5 & 98 & 0.98 & 44.16 & A-1-2 & Compressive & 99.0 & 98 & 0.99 & 242.12 \\
\hline A-2-1 & Tensile splitting & 73.0 & 73 & 1.00 & 41.08 & A-2-2 & Compressive & 73.0 & 73 & 1.00 & 183.45 \\
\hline A-3-1 & Tensile splitting & 73.0 & 73 & 1.00 & 49.48 & A-3-2 & Compressive & 73.0 & 74 & 1.01 & 217.26 \\
\hline A-4-1 & Tensile splitting & 73.5 & 73 & 0.99 & 28.06 & A-4-2 & Compressive & 73.5 & 74 & 1.01 & 73.46 \\
\hline A-5-1 & Tensile splitting & 72.5 & 73 & 1.01 & 25.36 & A-5-2 & Compressive & 73.0 & 73 & 1.00 & 120.43 \\
\hline A-6-1 & Tensile splitting & 73.0 & 73 & 1.00 & 40.26 & A-6-2 & Compressive & 73.0 & 74 & 1.01 & 195.54 \\
\hline A-7-1 & Tensile splitting & 73.5 & 73 & 0.99 & 26.33 & A-7-2 & Compressive & 73.5 & 73 & 0.99 & 144.40 \\
\hline A-8-1 & Tensile splitting & 73.0 & 72 & 0.99 & 41.62 & A-8-2 & Compressive & 73.5 & 74 & 1.01 & 161.85 \\
\hline A-9-1 & Tensile splitting & 73.5 & 75 & 1.02 & 34.80 & A-9-2 & Compressive & 72.5 & 73 & 1.01 & 161.14 \\
\hline A-10-1 & Tensile splitting & 72.5 & 73 & 1.01 & 22.77 & A-10-2 & Compressive & 73.0 & 73 & 1.00 & 125.92 \\
\hline A-11-1 & Tensile splitting & 73.5 & 73 & 0.99 & 20.44 & A-11-2 & Compressive & 73.5 & 73 & 0.99 & 120.44 \\
\hline A-12-1 & Tensile splitting & 73.0 & 73 & 1.00 & 23.69 & A-12-2 & Compressive & 72.5 & 73 & 0.99 & 111.41 \\
\hline B-1-1 & Tensile splitting & 73.0 & 73 & 1.00 & 36.26 & B-1-2 & Compressive & 73.5 & 72 & 0.98 & 160.48 \\
\hline B-2-1 & Tensile splitting & 73.5 & 73 & 0.99 & 34.26 & B-2-2 & Compressive & 73.0 & 73 & 1.00 & 130.01 \\
\hline B-3-1 & Tensile splitting & 73.5 & 70 & 0.95 & 30.72 & B-3-2 & Compressive & 73.5 & 70 & 0.95 & 131.43 \\
\hline B-4-1 & Tensile splitting & 73.5 & 70 & 0.95 & 29.20 & B- $4-2$ & Compressive & 73.5 & 70 & 0.95 & 196.10 \\
\hline B-5-1 & Tensile splitting & 73.0 & 73 & 1.00 & 17.35 & B-5-2 & Compressive & 73.5 & 72 & 0.98 & 186.28 \\
\hline B-6-1 & Tensile splitting & 73.5 & 74 & 1.01 & 38.18 & B-6-2 & Compressive & 73.5 & 73 & 0.99 & 132.79 \\
\hline B-7-1 & Tensile splitting & 73.0 & 74 & 1.01 & 37.64 & B-7-2 & Compressive & 73.0 & 73 & 1.00 & 129.80 \\
\hline B-8-1 & Tensile splitting & 73.5 & 73 & 0.99 & 34.42 & B-8-2 & Compressive & 73.5 & 73 & 0.99 & 111.68 \\
\hline B-9-1 & Tensile splitting & 73.5 & 73 & 0.99 & 42.64 & B-9-2 & Compressive & 73.5 & 73 & 0.99 & 153.36 \\
\hline B-10-1 & Tensile splitting & 73.5 & 73 & 0.99 & 40.48 & B-10-2 & Compressive & 73.0 & 72 & 0.99 & 129.65 \\
\hline B-11-1 & Tensile splitting & 73.5 & 73 & 0.99 & 48.48 & B-11-2 & Compressive & 73.5 & 72 & 0.98 & 135.82 \\
\hline B-12-1 & Tensile splitting & 73.5 & 72 & 0.98 & 42.62 & B-12-2 & Compressive & 73.5 & 73 & 0.99 & 275.46 \\
\hline B-13-1 & Tensile splitting & 73.5 & 73 & 0.99 & 47.34 & B-13-2 & Compressive & 73.5 & 74 & 1.01 & 192.14 \\
\hline B-14-1 & Tensile splitting & 73.5 & 72 & 0.98 & 39.76 & B-14-2 & Compressive & 73.5 & 74 & 1.01 & 136.07 \\
\hline B-15-1 & Tensile splitting & 73.5 & 70 & 0.95 & 20.53 & B-15-2 & Compressive & 73.5 & 70 & 0.95 & 120.86 \\
\hline B-16-1 & Tensile splitting & 73.0 & 73 & 1.00 & 20.32 & B-16-2 & Compressive & 73.5 & 72 & 0.98 & 108.14 \\
\hline C-1-1 & Tensile splitting & 73.5 & 73 & 0.99 & 33.78 & C-1-2 & Compressive & 73.0 & 73 & 1.00 & 100.45 \\
\hline C-2-1 & Tensile splitting & 73.0 & 73 & 1.00 & 33.70 & C-2-2 & Compressive & 73.0 & 73 & 1.00 & 89.58 \\
\hline C-3-1 & Tensile splitting & 73.5 & 73 & 0.99 & 37.94 & C-3-2 & Compressive & 73.5 & 72 & 0.98 & 76.64 \\
\hline C-4-1 & Tensile splitting & 73.5 & 72 & 0.98 & 34.64 & C- $4-2$ & Compressive & 73.5 & 73 & 0.99 & 80.27 \\
\hline C-5-1 & Tensile splitting & 73.5 & 73 & 0.99 & 40.94 & C-5-2 & Compressive & 73.5 & 73 & 0.99 & 110.00 \\
\hline C-6-1 & Tensile splitting & 73.5 & 73 & 0.99 & 26.33 & C-6-2 & Compressive & 73.5 & 74 & 1.01 & 138.09 \\
\hline C-7-1 & Tensile splitting & 73.5 & 73 & 0.99 & 36.10 & C-7-2 & Compressive & 73.5 & 73 & 0.99 & 68.36 \\
\hline C-8-1 & Tensile splitting & 73.0 & 73 & 1.00 & 34.38 & C-8-2 & Compressive & 73.0 & 72 & 0.99 & 90.91 \\
\hline C-9-1 & Tensile splitting & 73.5 & 73 & 0.99 & 28.38 & C-9-2 & Compressive & 73.5 & 73 & 0.99 & 107.07 \\
\hline C-10-1 & Tensile splitting & 73.5 & 73 & 0.99 & 30.80 & C-10-2 & Compressive & 73.0 & 72 & 0.99 & 61.20 \\
\hline C-11-1 & Tensile splitting & 73.0 & 73 & 1.00 & 32.08 & C-11-2 & Compressive & 73.5 & 73 & 0.99 & 86.87 \\
\hline C-12-1 & Tensile splitting & 73.5 & 73 & 0.99 & 34.54 & C-12-2 & Compressive & 73.0 & 73 & 1.00 & 87.90 \\
\hline D-1-1 & Tensile splitting & 73.0 & 70 & 0.96 & 32.70 & D-1-2 & Compressive & 73.5 & 70 & 0.95 & 82.07 \\
\hline D-2-1 & Tensile splitting & 73.5 & 71 & 0.97 & 25.61 & D-2-2 & Compressive & 74.0 & 73 & 0.99 & 138.60 \\
\hline D-3-1 & Tensile splitting & 73.5 & 72 & 0.98 & 29.28 & D-3-2 & Compressive & 73.0 & 73 & 1.00 & 68.38 \\
\hline D-4-1 & Tensile splitting & 73.0 & 72 & 0.99 & 23.20 & D-4-2 & Compressive & 73.0 & 72 & 0.99 & 65.78 \\
\hline D-5-1 & Tensile splitting & 73.5 & 73 & 0.99 & 25.18 & D-5-2 & Compressive & 73.5 & 74 & 1.01 & 110.32 \\
\hline D-6-1 & Tensile splitting & 73.5 & 73 & 0.99 & 31.02 & D-6-2 & Compressive & 73.0 & 72 & 0.99 & 65.35 \\
\hline D-7-1 & Tensile splitting & 73.0 & 72 & 0.99 & 21.62 & D-7-2 & Compressive & 73.5 & 73 & 0.99 & 44.14 \\
\hline D-8-1 & Tensile splitting & 99.5 & 98 & 0.98 & 37.06 & D-8-2 & Compressive & 99.5 & 95 & 0.95 & 139.54 \\
\hline
\end{tabular}


2.5. Size Effect. In the above technical specification [23], diameter of standard concrete core is $100 \mathrm{~mm}$. However, there are usually large amount of steel bars in the field testing structures; as a result, drilling standard cores may cause damage to the reinforcement. Therefore, nonstandard cores with smaller scale are widely adopted in actual engineering, as well as in this study. Besides, different guidelines or codes may also adopt specimens with different shapes or sizes. In order to make the test results of this study more generally applicable, the size effect of nonstandard core samples was discussed, and then, strength of core was converted to that of $150 \times 150 \times 150 \mathrm{~mm}$ concrete cube specimen, which is defined as standard specimen in common construction standards, such as Europe codes [24] and China standards [25].

2.5.1. Size Effect of Compressive Strength. Great deal of experimental studies conducted by China Academy of Building Research demonstrated that when the height-diameter ratio of core equals 1 , compressive strength of core samples with diameters ranging from 70 to $75 \mathrm{~mm}$ is identical to that of standard core samples, as well as $150 \times 150 \times 150 \mathrm{~mm}$ concrete cube specimens, which manifests that the size effect on compressive strength may not be considered [23]. Aitcin et al. [26] also showed that when the height equals diameter, no significant difference is observed between compressive strength of cores and cube specimens. Hence, this paper does not take account of the size effect on compressive strength. Furthermore, the compressive strengths of core samples in this study were regarded as the strengths of $150 \times 150 \times$ $150 \mathrm{~mm}$ concrete cube specimens [23].

2.5.2. Size Effect of Tensile Split Strength. Through experimental research and theoretical analysis, Bazant et al. [27], Duan et al. [28], and Rocco et al. [29, 30] show that the tensile splitting strength of concrete is strongly determined by the size of test specimen. Wide range of experimental studies were carried out on cubes, cylinder, and prisms to investigate the size effect of tensile splitting strength by Kadleček et al. [31]. It was demonstrated that the size effect highly depends on the areas of splitting fracture section rather than the shape of test specimens, which creates a unifying measurement for size effect. A generalized size effect formula was presented, which can be applied to cores or cubes obtained from existing structures. According to Kadleček et al. [31], the tensile splitting strength of concrete cores was converted to the strength of standard test specimen $(150 \times 150 \times 150 \mathrm{~mm})$. The size effect formula is given as [31]

$$
k_{p}=\frac{f_{\mathrm{ts}, \mathrm{cor}}}{f_{\mathrm{ts}}}=2 \cdot A^{-0.128},
$$

where $k_{p}$ is coefficient of size effect; $f_{\mathrm{ts}, \text { cor }}$ is the tensile splitting strength of drilled core samples; $f_{\mathrm{ts}}$ is the tensile splitting strength of standard test specimen $(150 \times 150 \times$ $150 \mathrm{~mm}) ; A$ is the area of splitting fracture section of concrete core $\left(\mathrm{cm}^{2}\right)$.

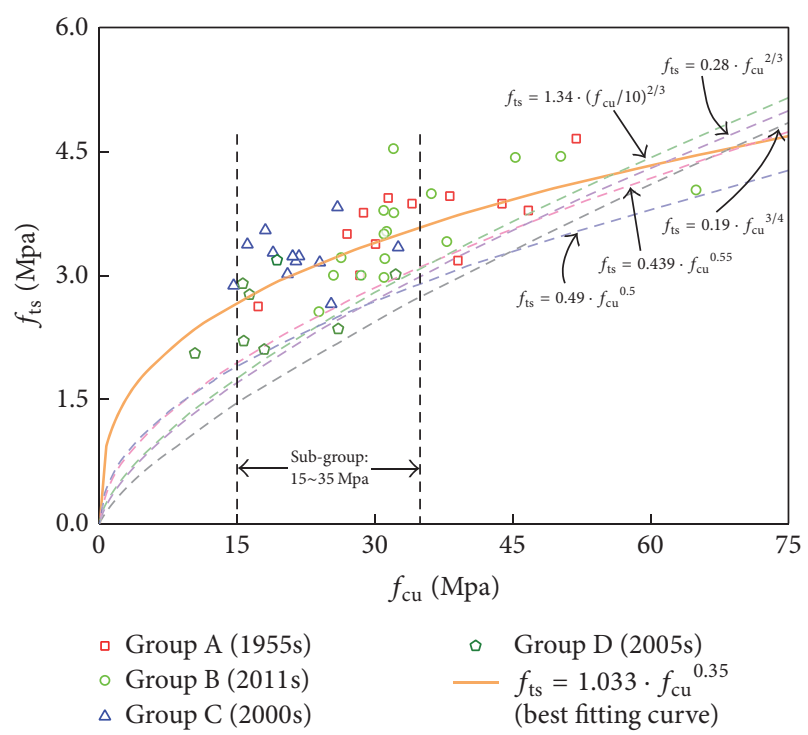

FIgURE 5: Compressive and splitting tensile strength.

\section{Results and Discussion}

3.1. The Relationship between Long-Term Compressive and Tensile Strength. According to Section 2.5, strengths of core samples were converted to strengths of standard test specimens, in order to improve practicability of the test result in this research. All of the 48 data points are presented in a coordinate system (Figure 5), with compressive strength as $x$-axis and tensile splitting strength as $y$-axis.

The experimental result signifies that compressive and tensile strength of concrete deteriorated by the marine environment of Zhoushan city for long term still present a certain regularity. The data points in Figure 5 distribute to the right oblique upward, forming a zonal shape. Although data points present discreteness, it is clear that as the raising of compressive strength, the tensile strength of the same concrete tends to increase as well. The correlation coefficient between compressive and splitting tensile strength is 0.72 , demonstrating that the two types of strength are still well positively correlated under environmental effects for long period of time.

Generally, exponential law is recommended by literatures or building guidelines to express the relationship between compressive and tensile strength of concrete cured under normal conditions and without environmental deterioration (fresh concrete) [25, 32-34] (Table 3, left column). In Table 3, $f_{\mathrm{cu}}$ and $f_{\mathrm{c}}$ are the compressive strength of $150 \times 150 \times$ $150 \mathrm{~mm}$ standard concrete cube and $150 / 300 \mathrm{~mm}$ cylinder, respectively. $f_{\mathrm{ts}}$ is the splitting tensile strength of $150 \times 150 \times$ $150 \mathrm{~mm}$ standard concrete cube. $f_{\mathrm{t}}$ represents the axial tensile strength of concrete. $f_{\mathrm{c}}$ and $f_{\mathrm{t}}$ are converted into $f_{\mathrm{cu}}$ and $f_{\mathrm{ts}}$ based on the conversion formula borrowed from other pieces of literature: $f_{\mathrm{cu}}=1.25 f_{\mathrm{c}}$ and $f_{\mathrm{t}}=0.9 f_{\mathrm{ts}}$ [32]. Then, for fresh concrete, the relationships between compressive and tensile strength in left column, Table 3 , are rewritten as the right column, where the strengths are $f_{\mathrm{cu}}$ and $f_{\mathrm{ts}}$, corresponding to the mechanical indexes of the test results 
TABLE 3: Compressive-tensile relationship.

$$
\left.\begin{array}{rl}
f_{\mathrm{t}}=0.26 \cdot f_{\mathrm{cu}}{ }^{2 / 3}[32] \\
f_{\mathrm{ts}}=0.55 \cdot \sqrt{f_{\mathrm{c}}}[34] \\
f_{\mathrm{t}}=1.4 \cdot\left(\frac{f_{\mathrm{c}}}{10}\right)^{2 / 3}[33] \\
f_{\mathrm{t}}=0.395 \cdot f_{\mathrm{cu}}{ }^{0.55}[25]
\end{array}\right\} \Longrightarrow\left\{\begin{array}{l}
f_{\mathrm{ts}}=0.28 \cdot f_{\mathrm{cu}}{ }^{2 / 3} \\
f_{\mathrm{ts}}=0.49 \cdot \sqrt{f_{\mathrm{cu}}} \\
f_{\mathrm{ts}}=1.34 \cdot\left(\frac{f_{\mathrm{cu}}}{10}\right)^{2 / 3} \\
f_{\mathrm{ts}}=0.439 \cdot f_{\mathrm{cu}}^{0.55} \\
f_{\mathrm{ts}}=0.19 \cdot f_{\mathrm{cu}}^{3 / 4}[32]
\end{array}\right.
$$

TABLE 4: The SSE of recommended functions.

\begin{tabular}{lc}
\hline Proposed functions & SSE \\
\hline$f_{\mathrm{ts}}=0.19 f_{\mathrm{cu}}^{3 / 4}$ & 58.0081 \\
$f_{\mathrm{ts}}=0.439 f_{\mathrm{cu}}^{0.55}$ & 25.4530 \\
$f_{\mathrm{ts}}=1.34\left(f_{\mathrm{cu}} / 10\right)^{2 / 3}$ & 31.1486 \\
$f_{\mathrm{ts}}=0.28 f_{\mathrm{cu}}^{2 / 3}$ & 36.1975 \\
$f_{\mathrm{ts}}=0.49 f_{\mathrm{cu}}^{0.5}$ & 34.7893 \\
\hline
\end{tabular}

in this study. Whether these existing compressive-tensile strength relationships (Table 3) for fresh concrete are still suitable for the deteriorated concrete in this paper or not was further explored.

As observed from Figure 5, all the correlations between compressive and tensile strength for fresh concrete recommended by building codes or literatures are increasing functions that basically present the tendency of the experimental results in this research. However, from the deviation distance between test results and these proposed function curves in Figure 5, none of them expresses the compressive-tensile strength relationship of the deteriorated concrete accurately enough. The SSE (sum of squares due to error, calculated as (4)), which is one of important indexes presenting goodness of curve fitting, is shown in Table 4.

$$
\mathrm{SSE}=\sum_{i=1}^{n}\left(y_{i}-\widehat{y}_{i}\right)^{2},
$$

where $y_{i}$ and $\hat{y}_{i}$ represent the experimental and predicted (through the proposed functions) tensile strength of concrete and $n$ is the number of data analysed.

The SSE statistic is the least-squares error of the fit, with a value closer to zero indicating a better fit. Nevertheless, the SSE of all proposed functions listed in this paper are large, together with quite small $R$-square statistics, indicating poor fitting effects to the experimental results. In addition, the index as (theoretical value - experimental value)/experimental value is used to reflect the errors between experimental values and model predicted values (Figures 6(a) 6(e)). It is clear that all the relations for fresh concrete $f_{\mathrm{ts}}=0.19 f_{\mathrm{cu}}{ }^{3 / 4}, f_{\mathrm{ts}}=0.439 f_{\mathrm{cu}}{ }^{0.55}, f_{\mathrm{ts}}=$ $1.34\left(f_{\mathrm{cu}} / 10\right)^{2 / 3}, f_{\mathrm{ts}}=0.28 f_{\mathrm{cu}}{ }^{2 / 3}$, and $f_{\mathrm{ts}}=0.49 f_{\mathrm{cu}}{ }^{0.5}$ are inclined to underestimate the tensile strength. One possible reason may be that, after environmental deterioration for long time, compressive strength exhibits more degradation than tensile strength, which increases the ratio of tensile strength to compressive strength.
From the above discussion, it is shown that all the compressive-tensile strength relationships for fresh concrete listed in this study are not applicable to the environmentally deteriorated concrete with satisfactory accuracy, which may imply that appropriate revisions are needed. Hence, adjustment for parameters in exponential function was made aiming to promote the goodness of curve fitting. The compressive-tensile strength relationship in exponential form can be written as

$$
f_{\mathrm{ts}}=a \cdot f_{\mathrm{cu}}{ }^{b},
$$

where $a$ and $b$ are fitting parameters.

According to the test results, the function which best presents the relationship between compressive strength and tensile strength in this study was obtained through nonlinear curve fitting (Figure 5):

$$
f_{\mathrm{ts}}=1.02 \cdot f_{\mathrm{cu}}^{0.36} \text {. }
$$

The SSE and $R$-square of such fitting are 8.1256 and 0.5344. Also, the predicting error shown in Figure 6(f) is reasonably moderate, which confirms that, even for the concrete deteriorated by marine environment for long period of time, the compressive-tensile strength relationship can also be rationally described by exponential function with acceptable accuracy, if the parameters of function were properly determined. This best fitting function (see (6)) can be regarded as a modified version of the compressivetensile strength relationship recommended by guidelines or literatures for fresh concrete.

Furthermore, although concrete cores from groups A, $\mathrm{B}, \mathrm{C}$, and $\mathrm{D}$ are deteriorated by marine environment for different periods $(61,5,16$, and 11 years) and present various ranges of strengths, they commonly share the same subgroup (compressive strength ranging from $15 \mathrm{Mpa}$ to $35 \mathrm{Mpa}$, Figure 7), which may imply that the compressive-tensile strength correlation $f_{\mathrm{ts}}=1.02 f_{\mathrm{cu}}{ }^{0.36}$ is adequately suitable for concrete with compressive strength from $15 \mathrm{Mpa}$ to $35 \mathrm{Mpa}$, regardless of the exact deteriorated period within several decades.

In concrete technology, the aggregate strength is usually not a factor considered in normal strength concrete because, with the exception of lightweight aggregates, the aggregate partial is several times stronger than the matrix and the interfacial transition zone in concrete. In other words, with most natural aggregates the strength of the aggregates is hardly utilized because the failure is determined by the other two phases (matrix and interfacial transition zone). However, aggregate characteristics other than strength, such as the size, shape, surface texture, grading, and mineralogy, are known to affect concrete strength in varying degrees. It may be anticipated that, independent of the water-cement ratio, the size, shape, and surface texture of aggregate particles would influence the characteristics of the interfacial transition zone and therefore affect concrete strength. Furthermore, since the interfacial transition zone characteristics have more effect on the tensile strength of concrete compared to the compressive strength, it is to be expected that with a given concrete mixture any changes 


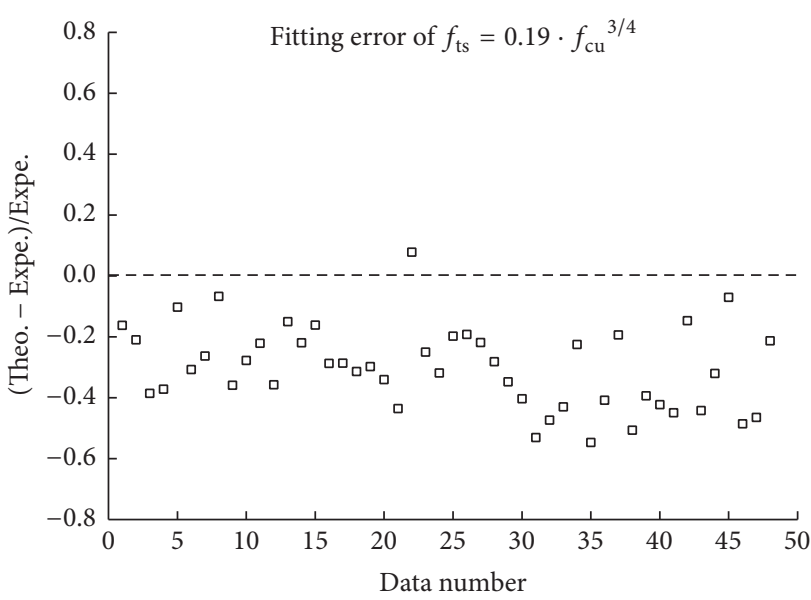

(a)

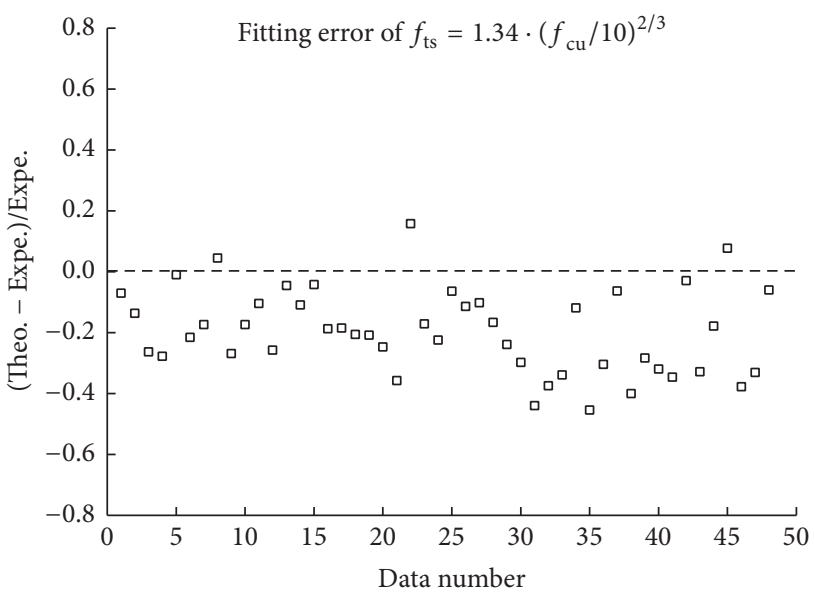

(c)

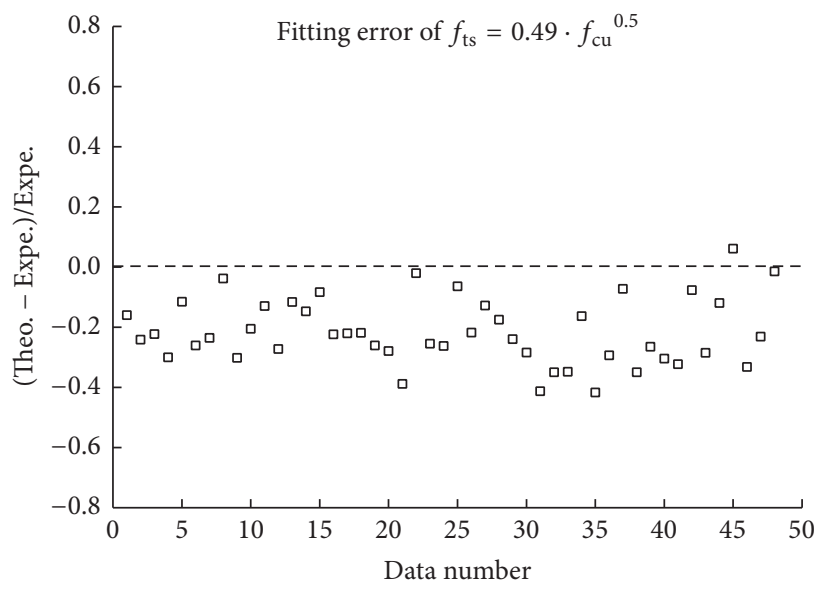

(e)

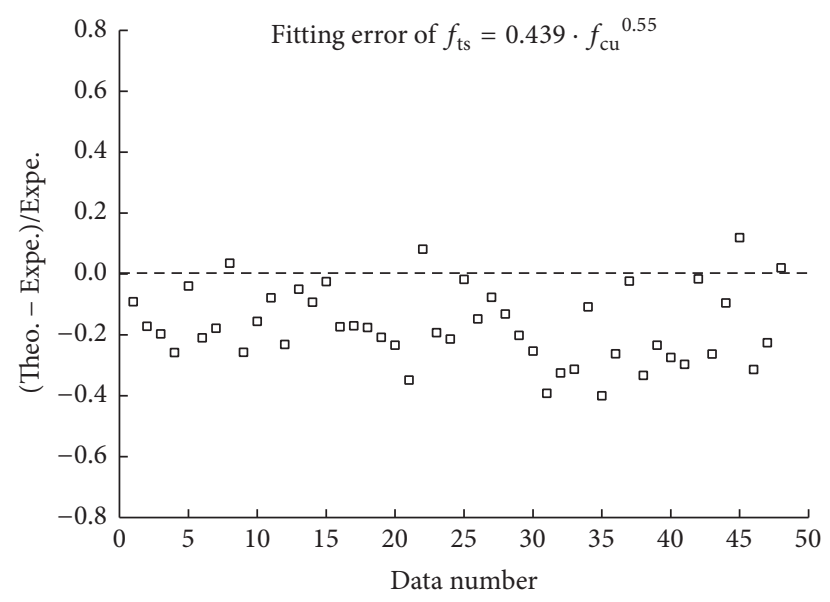

(b)

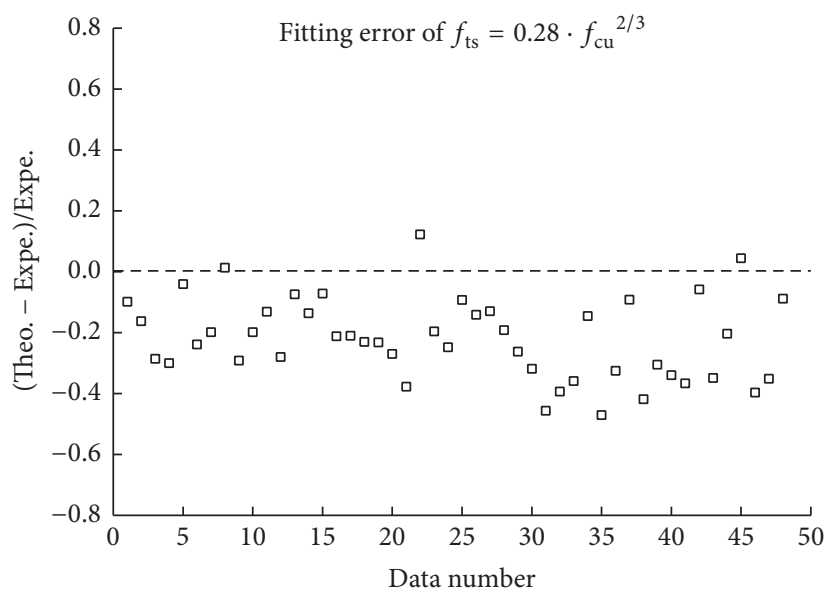

(d)

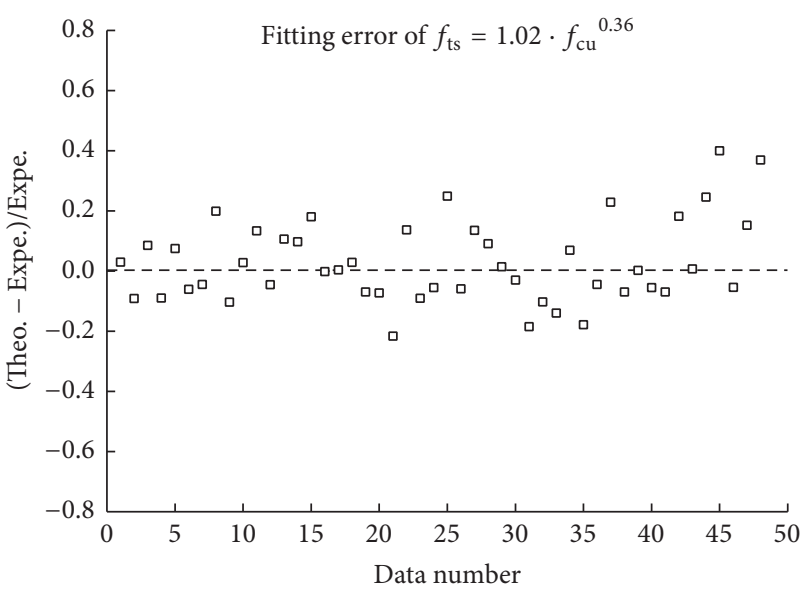

(f)

Figure 6: Prediction errors.

in the coarse aggregates properties would influence the tensile-compressive strength relationship of the material. Wang et al. [35] investigated the effects of the maximum aggregate size $d_{\max }$ on concrete tensile strength and fracture toughness. Considering that concrete is highly heterogonous, inclusion of $d_{\max }$ in a final relation of concrete fracture modelling is necessary. A simple methodology for analysing quasibrittle fracture of small notched three-point-bend concrete specimen was presented to determine tensile strength and fracture toughness. Fictitious crack growth before the maximum load is considered by the maximum aggregate size $d_{\text {max }}$. Also, the tensile strength controlled $\left(f_{\mathrm{t}}\right.$-controlled $)$ 


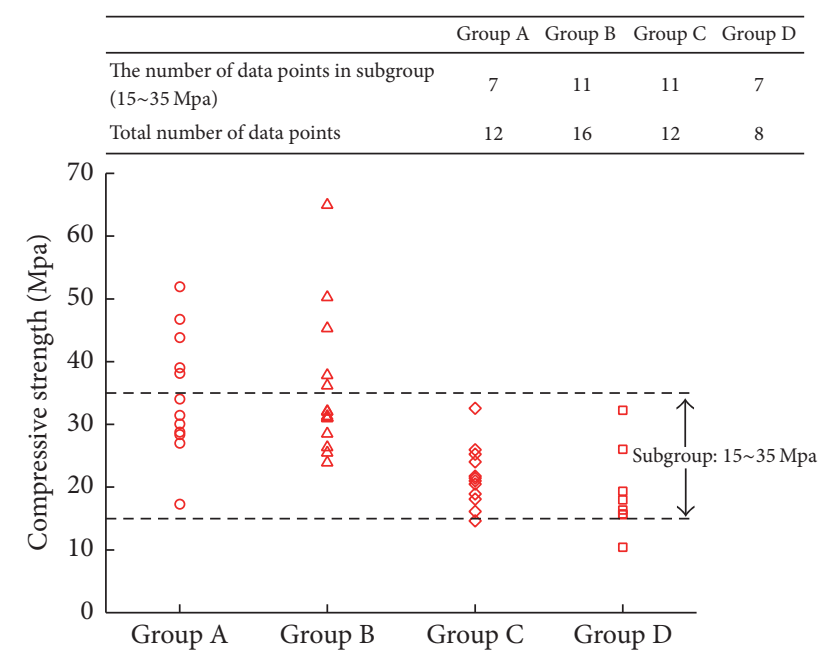

Figure 7: The subgroup shared by groups A, B, C, and D.

failure and fracture toughness controlled ( $K_{\mathrm{IC}}$-controlled) failure link $d_{\max }$ to the fictitious crack growth at the peak load [36]. However, in the experimental research of this study, since the places for drilling core samples had existed for years, the authors of this paper were not capable of obtaining enough original engineering data in detail, such as mix proportion, size of aggregate, and aggregate grading. Although, aggregates near surface are roughly shown in the photographs of core sample (e.g., Figure 3), the information of aggregate such as the maximum size, shape, and distribution cannot be accurately obtained since each sample has been incised and processed. Hence the characteristics of aggregate are not particularly considered in Section 2.4. In future research, taking aggregate into analysis may be the further target, which might add more profound explanations to the test result of this study.

\subsection{Prediction of Long-Term Strength under Marine Environment}

3.2.1. Prediction of Long-Term Compressive Strength. Based on sufficient investigations on existing costal buildings in China and Japan, Niu [37] empirically concluded a possible model for estimating long-term compressive strength of concrete under marine environment. A nonstationary stochastic process is applied to describe the changing law of concrete compressive strength with time. At a certain time $t$, the compressive strength is regarded as a random variable obeying normal distribution. The probability density function at any time is given as follows:

$$
p_{f}(x, t)=\frac{1}{\sqrt{2 \pi} \sigma_{f}(t)} \exp \left[-\frac{\left(x-\mu_{f}(t)\right)^{2}}{2 \sigma_{f}^{2}(t)}\right] \text {, }
$$

where $\mu_{f}(t), \sigma_{f}(t)$ is mean value and standard derivation of concrete compressive strength after time $t$ (year), which can be calculated as

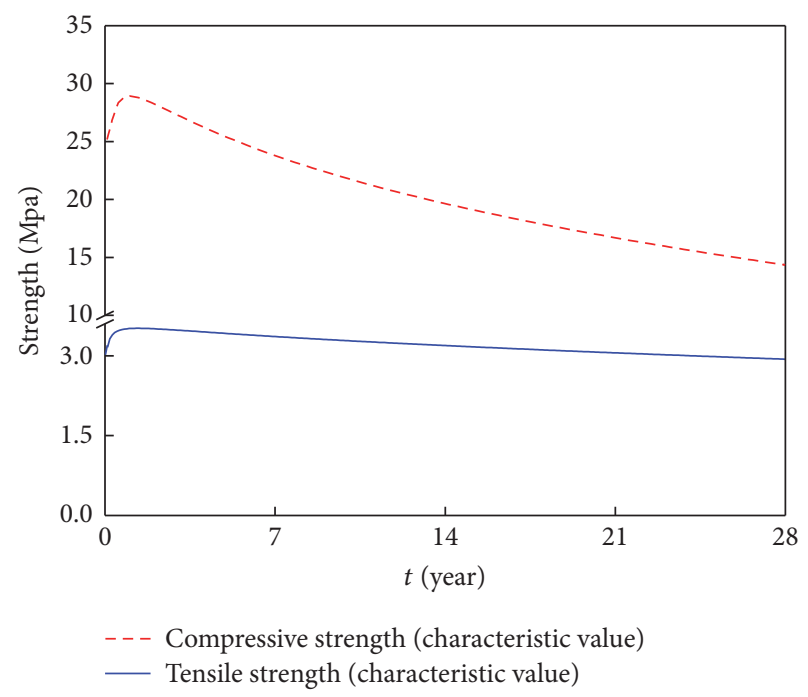

FIGURE 8: The predicted compressive and tensile strength.

$$
\begin{aligned}
& \mu_{f}(t)=\xi(t) \mu_{0}, \\
& \sigma_{f}(t)=\eta(t) \sigma_{0},
\end{aligned}
$$

where $\mu_{0}, \sigma_{0}$ are mean value and standard derivation of concrete compressive strength at 28 days $(t=0) ; \xi(t)$ and $\eta(t)$ are two functions of time, which are given as

$$
\begin{aligned}
\xi(t) & =1.2488 e^{-0.0347(\ln t-0.3468)^{2}} \\
\eta(t) & =0.0143 t+1.6024
\end{aligned}
$$

Therefore, when $\mu_{0}, \sigma_{0}$ are given, the probability density function (PDF) of concrete compressive strength at any time is determined by (7) (10). Then, compressive strength with specific probability assurance rate at given time can be determined through the PDF. For example, as stipulated in the Europe code [24] and China standard [25], the probability assurance of the concrete characteristic compressive strength is $95 \%$. Based on the PDF, characteristic compressive strength can be obtained by numerical calculation or simply by the following formula (see (11)), since the probability is normally distributed.

$$
f_{\mathrm{cu}, k}(t)=\mu_{f}(t)-1.645 \cdot \sigma_{f}(t) .
$$

For instance, the mean value and standard derivation of concrete compressive strength at 28 days are $31.15 \mathrm{Mpa}$ and $3.738 \mathrm{Mpa}$, respectively. According to the above Niu's model [37], the characteristic compressive strength $\left(f_{\mathrm{cu}, k}\right)$ at any time is worked out, as shown in Figure 8. Strength with other probability assurance rates can be calculated similarly. Niu's model provides a possible method that is able to predict longterm concrete compressive strength under marine conditions including marine atmosphere, tidal areas, and immersed regions by seawater [37, 38]. According to the predicted results by Niu's model, the compressive strength of concrete under marine environment shows increment in first 1 or 2 years after casting. This could be due to the continuing 
internal chemical reactions within concrete, which gives rise to strength growth. For instance, formation of salt crystals contributes towards enhancing cohesion among aggregates which induces strength increase. Under long-term environmental effects, corrosive substance attacks and the expansions or shrinkages caused by environments would induce cracks within concrete, especially for those with inadequate mix design. Once the cracks are initiated, it allows the further penetration of more harmful and corrosive substances, which ultimately reduces the durability and strength of concrete in a substantial manner. For that reason, concrete strength tends to degrade with time in later period. Such possible characteristic of strength change was concluded by Niu [37] through numerous investigations on coastal constructions in China and Japan.

3.2.2. Prediction of Long-Term Tensile Strength. In Section 3.1, for concrete with compressive strength ranging from $15 \mathrm{Mpa}$ to $35 \mathrm{Mpa}$, the recommended exponential function by this study $f_{\mathrm{ts}}=1.02 f_{\mathrm{cu}}{ }^{0.36}$ is applied to describe the compressivetensile strength correlation within acceptable error, regardless of the specific deteriorated period among several decades.

Similar to Niu's model, both compressive and tensile strength are regarded as stochastic processes in this study, which are two random variables at certain time. The experimental research in this paper essentially presents the relationship (see (6)) between those two random variables. Then, at given time $t$, the PDF of tensile strength can be derived through the theory of probability. An example is provided herein to elucidate the method for calculating the statistic distribution of tensile strength, and then, the long-term tensile strength is predicted.

For tensile strength, the Cumulate Distribution Function $(\mathrm{CDF})$ is derived as

$$
\begin{aligned}
F_{f_{\mathrm{ts}}(t)}(x) & =P\left\{f_{\mathrm{ts}}(t)<x\right\}=P\left\{1.02 \cdot f_{\mathrm{cu}}(t)^{0.36}<x\right\} \\
& =P\left\{f_{\mathrm{cu}}(t)<\frac{1}{1.02} \cdot x^{1 / 0.36}\right\} \\
& =F_{f_{\mathrm{cu}}(t)}\left(\frac{1}{1.02} \cdot x^{1 / 0.36}\right)
\end{aligned}
$$

where $f_{\mathrm{ts}}(t)$ and $f_{\mathrm{cu}}(t)$ are the tensile strength and compressive strength at given time $t$, which are both random variables. $F_{f_{\mathrm{ts}}(t)}(x)$ and $F_{f_{\mathrm{cu}}(t)}(x)$ are the Cumulate Distribution Function (CDF) of random variable $f_{\mathrm{ts}}(t), f_{\mathrm{cu}}(t)$.

Then, the probability density function of tensile strength can be obtained through differential operation as

$$
\begin{aligned}
p_{f_{\mathrm{ts}}(t)} & =\frac{d F_{f_{\mathrm{ts}}(t)}(x)}{d x}=\frac{d F_{f_{\mathrm{cu}}(t)}\left((1 / 1.02) \cdot x^{1 / 0.36}\right)}{d x} \\
& =\frac{1}{1.02} \cdot \frac{1}{0.36} \cdot x^{(1 / 0.36-1)} p_{f_{\mathrm{cu}}(t)}\left(\frac{1}{1.02} \cdot x^{1 / 0.36}\right) .
\end{aligned}
$$

According to Niu's research [35, 36], at given time $t$, concrete compressive strength obeys normal distribution as (8); hence

$$
\begin{aligned}
& p_{f_{\mathrm{cu}}(t)}\left(\frac{1}{1.02} x^{1 / 0.36}\right) \\
& \quad=\frac{1}{\sqrt{2 \pi} \sigma_{f}(t)} \exp \left[-\frac{\left((1 / 1.02) x^{1 / 0.36}-\mu_{f}(t)\right)^{2}}{2 \sigma_{f}^{2}(t)}\right] .
\end{aligned}
$$

Bringing (14) into (13), the PDF of tensile strength at certain time $t$ is obtained:

$$
\begin{aligned}
& p_{f_{\mathrm{ts}}(t)} \\
& \quad=\frac{2.72 \cdot x^{1.78}}{\sqrt{2 \pi} \sigma_{f}(t)} \exp \left[-\frac{\left((1 / 1.02) x^{1 / 0.36}-\mu_{f}(t)\right)^{2}}{2 \sigma_{f}^{2}(t)}\right] .
\end{aligned}
$$

Based on the statistic distribution of $f_{\mathrm{ts}}(t)$ shown as (15), tensile strength with specific probability assurance rate such as $95 \%$ (characteristic value) can be calculated through numerical calculation, as well as tensile strength with some other probability assurance rates. The predicted tensile strength is shown in Figure 8. Resembling to the long-term compressive strength, the long-term tensile strength presents slight increase in the initial period and then decreases with time; however, it appears as a relatively moderate tendency. This section provides a possible method for estimating longterm tensile strength of concrete under marine environment. Using the method proposed herein, the concrete tensile strength is predicted in several years or decades, rather than several days or weeks only.

\section{Conclusions and Prospects}

An experimental research was carried out in this study to investigate the relationship between the long-term compressive and tensile strength of concrete under realistic marine environment. Exponential function obtained through nonliner fitting is recommended to quantitatively describe such correlation. Based on the tests results, a possible method for predicting long-term tensile strength is developed. According to the finds in this study, the following conclusions can be drawn:

(1) For concrete exposing to marine environments of Zhoushan city for long period as several years or decades, compressive and tensile strength present certain regularity: as compressive strength increasing, the tensile strength tends to increase as well. The correlation coefficient between the two types of strength is 0.72 , indicating that they are well positively correlated after environmental deterioration.

(2) The exponential functions for fresh concrete $\left(f_{\mathrm{ts}}=\right.$ $0.19 f_{\mathrm{cu}}{ }^{3 / 4}, f_{\mathrm{ts}}=0.439 f_{\mathrm{cu}}^{0.55}, f_{\mathrm{ts}}=1.34\left(f_{\mathrm{cu}} / 10\right)^{2 / 3}$, $f_{\mathrm{ts}}=0.28 f_{\mathrm{cu}}^{2 / 3}$, and $f_{\mathrm{ts}}=0.49 f_{\mathrm{cu}}^{0.5}$ ) proposed by building guidelines or literatures only roughly describe the overall tendency of compressive-tensile 
strength relationship for deteriorated concrete. Large SSE along with quite small $R$-square statistics indicate their poor fitting effects. By adjusting the parameters of exponential function, a best fitting curve $\left(f_{\mathrm{ts}}=\right.$ $1.02 f_{\mathrm{cu}}{ }^{0.36}$ ) is recommended by this paper, which demonstrates that the exponential model can be extensively used to describe the compressive-tensile strength relationships for both fresh and deteriorated concrete. Moreover, the best fitting function $\left(f_{\mathrm{ts}}=\right.$ $1.02 f_{\mathrm{cu}}{ }^{0.36}$ ) may be suitable for concrete with compressive strength ranging from $15 \mathrm{Mpa}$ to $35 \mathrm{Mpa}$, regardless of the specific deteriorating period within several decades.

(3) A potential tensile strength predicting method is established within the frame-work of probability analysis. The compressive and tensile strengths of concrete are regarded as two stochastic processes. The test in this study essentially investigated the relationship of them. Based on formerly known probability distributions of compressive strength from literature, the probability distributions of tensile strength at given time $t$ is determined through statistical analysis. Then, tensile strength with specific probability assurance rate (such as 95\%) can be worked out and prediction of long-term tensile strength is accomplished, which may provide meaningful information in life-through estimations, durability assessment, or structural health monitoring.

In future studies, aiming to experimentally characterize a more representative relationship between long-term compressive and tensile strength of concrete under marine environment, the authors of this paper will obtain added concrete samples from various coastal areas, not limited to Zhoushan city. The characteristics of aggregate may be taken into analysis. Also, the effectiveness of the method in this paper for predicting long-term tensile strength will be further verified.

\section{Conflicts of Interest}

The authors declare that they have no conflicts of interest.

\section{Acknowledgments}

The study was financially supported by the project named Service Life Prediction of Strengthened RC Beam (KJ2015030) and provided by Chongqing Administration of Land, Resources and Housing. The test conducted in this paper was under the help of Yong Cheng Construction Detection Research Co. Ltd., Ningbo.

\section{References}

[1] C. Gaedicke, A. Torres, K. C. T. Huynh, and A. Marines, "A method to correlate splitting tensile strength and compressive strength of pervious concrete cylinders and cores," Construction and Building Materials, vol. 125, pp. 271-278, 2016.

[2] K. Yan, H. Xu, G. Shen, and P. Liu, "Prediction of splitting tensile strength from cylinder compressive strength of concrete by support vector machine," Advances in Materials Science and Engineering, vol. 2013, Article ID 597257, 2013.

[3] M. H. Severcan, "Prediction of splitting tensile strength from the compressive strength of concrete using GEP," Neural Computing and Applications, vol. 21, no. 8, pp. 1937-1945, 2012.

[4] M. Saridemir, "Empirical modeling of splitting tensile strength from cylinder compressive strength of concrete by genetic programming," Expert Systems with Applications, vol. 38, no. 11, pp. 14257-14268, 2011.

[5] F. A. Oluokun, "Prediction of concrete tensile strength from its compressive strength. Evaluation of existing relations for normal weight concrete," ACI Materials Journal, vol. 88, no. 3, pp. 302-309, 1991.

[6] M. Weber and C. Thiele, "Correlation between the compressive and tensile strength of old concretes: applicability of the relationship described by DIN EN 1992-1-1," Beton- Und Stahlbetonbau, vol. 111, no. 10, pp. 635-644, 2016.

[7] B. Li, L. Cai, K. Wang, and Y. Zhang, "Prediction of the residual strength for durability failure of concrete structure in acidic environments," Journal Wuhan University of Technology, Materials Science Edition, vol. 31, no. 2, pp. 340-344, 2016.

[8] Y. Zhou, H. Tian, L. Sui, F. Xing, and N. Han, "Strength deterioration of concrete in sulfate environment: an experimental study and theoretical modeling," Advances in Materials Science and Engineering, vol. 2015, Article ID 951209, 13 pages, 2015.

[9] J. Cai, F. Zhang, W. Cui, S. Chen, and P. Liu, "Concrete strength and deformation property under sea water erosion environment," Advanced Materials Research, vol. 446-449, pp. 2554-2559, 2012.

[10] M. Ramli, W. H. Kwan, and N. F. Abas, "Strength and durability of coconut-fiber-reinforced concrete in aggressive environments," Construction and Building Materials, vol. 38, pp. 554566, 2013.

[11] H.-S. Shang, T.-H. Yi, and X.-X. Guo, "Study on strength and ultrasonic velocity of air-entrained concrete and plain concrete in cold environment," Advances in Materials Science and Engineering, vol. 2014, Article ID 706986, 7 pages, 2014.

[12] B. S. Thomas, R. C. Gupta, P. Mehra, and S. Kumar, "Performance of high strength rubberized concrete in aggressive environment," Construction and Building Materials, vol. 83, article no. 6441, pp. 320-326, 2015.

[13] J. O. Okeniyi, I. O. Oladele, O. M. Omoniyi, C. A. Loto, and A. P. Popoola, "Inhibition and compressive-strength performance of $\mathrm{Na} 2 \mathrm{Cr} 2 \mathrm{O} 7$ and $\mathrm{C} 10 \mathrm{H} 14 \mathrm{~N} 2 \mathrm{Na} 2 \mathrm{O} 8.2 \mathrm{H} 2 \mathrm{O}$ in steel-reinforced concrete in corrosive environments," Canadian Journal of Civil Engineering, vol. 42, no. 6, pp. 408-416, 2015.

[14] W. H. Kwan, M. Ramli, and C. B. Cheah, "Flexural strength and impact resistance study of fibre reinforced concrete in simulated aggressive environment," Construction and Building Materials, vol. 63, pp. 62-71, 2014.

[15] M. Ramli, W. H. Kwan, and N. F. Abas, "Application of noncorrosive barchip fibres for high strength concrete enhancements in aggressive environments," Composites Part B: Engineering, vol. 53, pp. 134-144, 2013.

[16] X. Yuan, B. Li, G. Cui, S. Zhao, and M. Zhou, "Effect of fly ash and early strength agent on durability of concrete exposed to the cyclic sulfate environment," Journal Wuhan University of Technology, Materials Science Edition, vol. 25, no. 6, pp. 10651069, 2010.

[17] E. Güneyisi, M. Gesoğlu, and K. Mermerdaş, "Strength deterioration of plain and metakaolin concretes in aggressive sulfate 
environments," Journal of Materials in Civil Engineering, vol. 22, no. 4, pp. 403-407, 2010.

[18] J. P. Gorninski, D. C. Dal Molin, and C. S. Kazmierczak, "Strength degradation of polymer concrete in acidic environments," Cement and Concrete Composites, vol. 29, no. 8, pp. 637645, 2007.

[19] M. Ismail, B. Muhammad, and M. E. Ismail, "Compressive strength loss and reinforcement degradations of reinforced concrete structure due to long-term exposure," Construction and Building Materials, vol. 24, no. 6, pp. 898-902, 2010.

[20] P. K. Mehta, "Durability of concrete exposed to marine environment - A fresh look," ACI Structure Journal, vol. 109, pp. 1-30, 1988.

[21] M. Shekarchi, A. Rafiee, and H. Layssi, "Long-term chloride diffusion in silica fume concrete in harsh marine climates," Cement and Concrete Composites, vol. 31, no. 10, pp. 769-775, 2009.

[22] G. W. Washa and K. F. Wendt, "Fifty year properties of concrete," American Concrete Institute, vol. 72, no. 1, pp. 20-28, 1975.

[23] China Engineering Construction Standardization Association, CECS 03: 2007 Technical Specification for Testing Concrete Strength with Drilled Core, China Building Industry Press, Beijing, China, 2007.

[24] European Committee for Standardization, Concrete-Part 1: Specification, Performance, Production and Conformity, European Committee, 2006.

[25] Ministry of Housing and Urban-Rural Development of the People's Republic of China, GB 50010-2010 Code for Design of Concrete Structures, China Building Industry Press, Beijing, China, 2010.

[26] P. C. Aitcin, S. L. Sarkar, and P. Laplante, "Long-term characteristics of a very high strength concrete," Concrete International, vol. 12, no. 1, pp. 40-44, 1990.

[27] Z. P. Bazant, M. T. Kazemi, T. Hasegawa, and J. Mazars, "Size effect in Brazilian split-cylinder tests. Measurements and fracture analysis," ACI Materials Journal, vol. 88, no. 3, pp. 325$332,1991$.

[28] K. Duan, X. Hu, and F. H. Wittmann, "Scaling of quasi-brittle fracture: Boundary and size effect," Mechanics of Materials, vol. 38, no. 1-2, pp. 128-141, 2006.

[29] C. Rocco, G. V. Guinea, J. Planas, and M. Elices, "Size effect and boundary conditions in the Brazilian test: experimental verification," Materials and Structures, vol. 32, no. 217, pp. $210-$ 217, 1999.

[30] C. Rocco, G. V. Guinea, J. Planas, and M. Elices, "Size effect and boundary conditions in the brazilian test: theoretical analysis," Materials Structures, vol. 32, pp. 437-444, 1999.

[31] V. Kadleček, S. Modrý, and V. Kadleček, "Size effect of test specimens on tensile splitting strength of concrete: general relation," Materials and Structures, vol. 35, no. 1, pp. 28-34, 2002.

[32] Z. Guo, Theory of Reinforced Concrete, Tsinghua University Press, Beijing, China, 2013.

[33] International Federation for Structural Concrete (FIB), FIB056Model Code 2010, Concrete Structures, DCC Document Competence Center Siegmar Kästl e.K., Germany, Lausanne, Switzerland, 2010.

[34] ACI committee 318-14, Building Code Requirements for Structural Concrete, American Concrete Institute, Farmington Hills, Mich, USA, 2014.
[35] Y. Wang, X. Hu, L. Liang, and W. Zhu, "Determination of tensile strength and fracture toughness of concrete using notched 3-pb specimens," Engineering Fracture Mechanics, vol. 160, pp. 6777, 2016.

[36] J. Guan, X. Hu, and Q. Li, "In-depth analysis of notched 3-p-b concrete fracture," Engineering Fracture Mechanics, vol. 165, pp. 57-71, 2016.

[37] D. Niu, "Changing models of concrete strength along with time in marine environment," Journal of Xian University of Architecture and Technology, vol. 27, no. 03, pp. 49-52, 1995.

[38] Q. Zhao, Y. Yong, and G. Sen, "Reliability estimation of inservice tunnel shield capacity," in Proceedings of the International Conference on Pipelines and Trenchless Technology 2009, ICPTT 2009: Advances and Experiences with Pipelines and Trenchless Technology for Water, Sewer, Gas, and Oil Applications, pp. 1783-1792, Shanghai, China, 2009. 

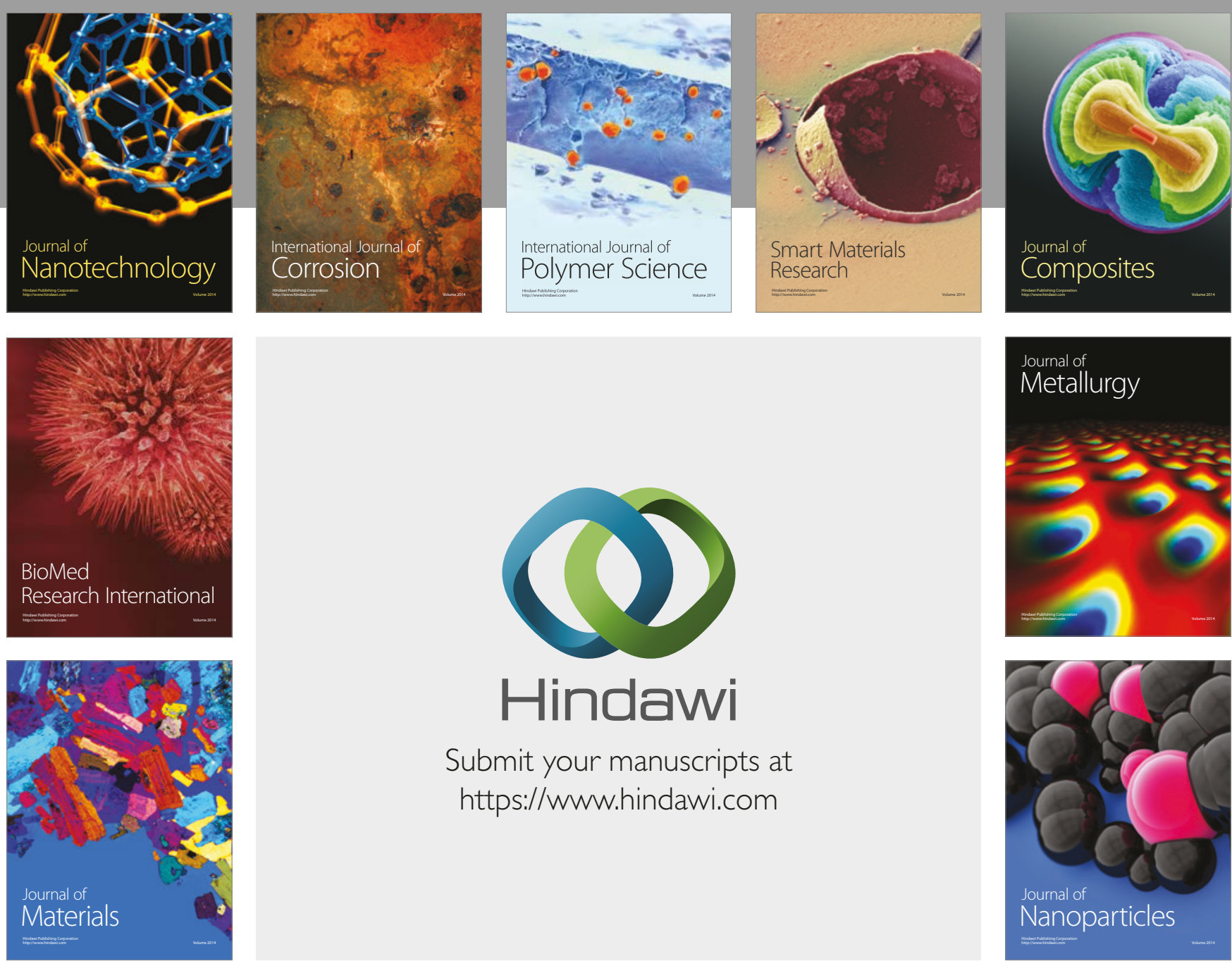

\section{Hindawi}

Submit your manuscripts at

https://www.hindawi.com
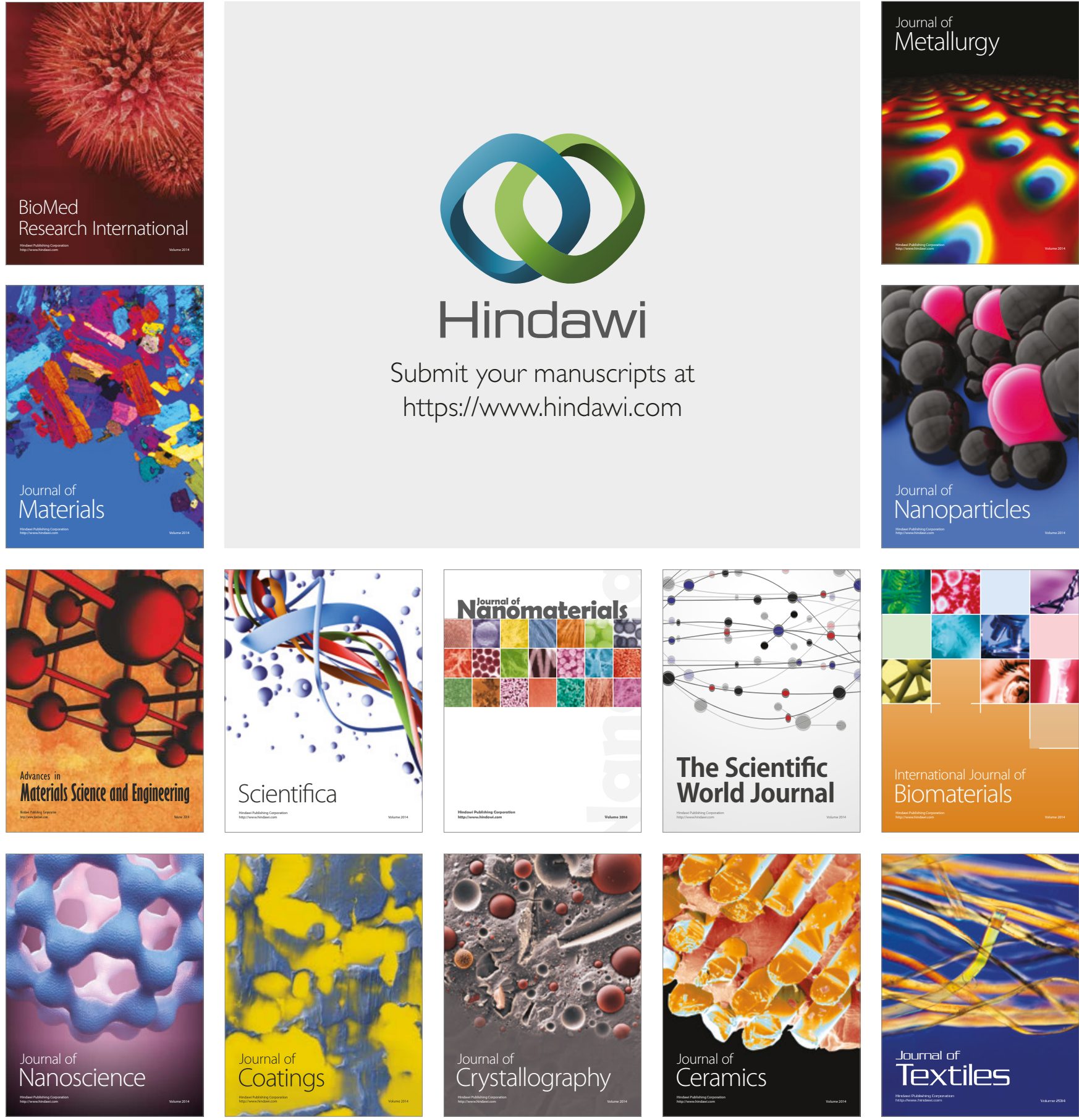

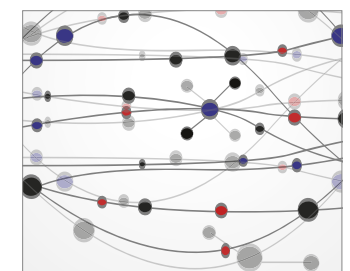

The Scientific World Journal
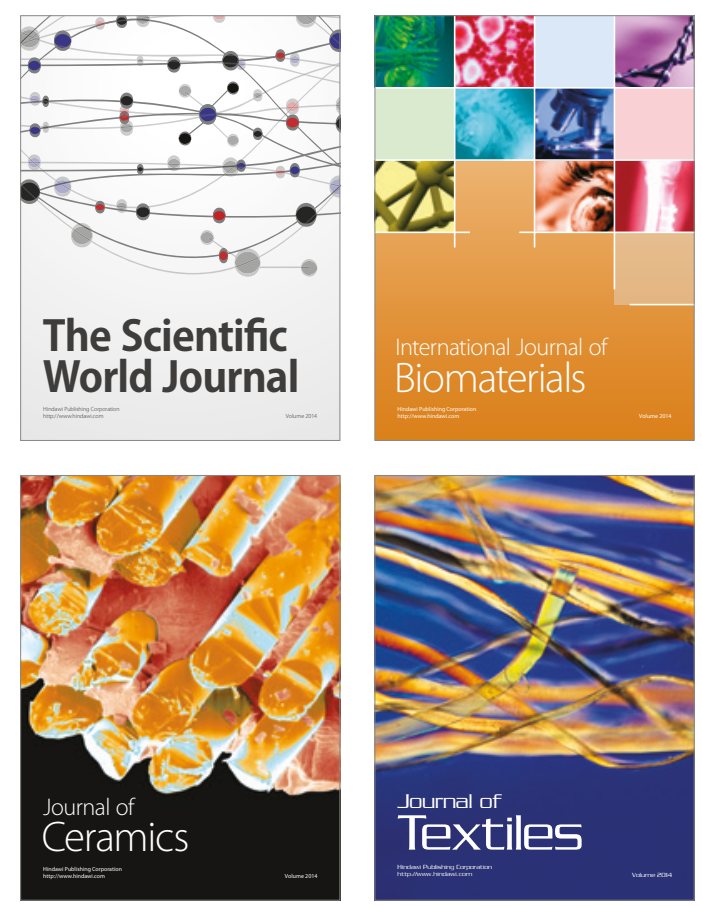